\title{
ENTREPRENEURSHIP OPPORTUNITIES INNOVATIONS AND ECOSYSTEM
}

\author{
Kshitij Shinghal, Amit Saxena \\ Dept. of E\&C Engg., Moradabad Institute of Technology \\ Moradabad, U.P., India
}

\begin{abstract}
With recent developments and efforts by the government everyone is aware and has understood the importance of including study of entrepreneurship in curriculum. That is why there is a shift of entrepreneurship course from elective course or a single chapter in subject to a full-fledged course. This paper focuses on identifying entrepreneurship opportunities innovations and ecosystem for engineering students specially taking into consideration Moradabad city. Moradabad is famous for exporting brass and other metal handicraft items. It is also known as brass city of India.
\end{abstract}

KEYWORDS: Entrepreneurship, innovations, ecosystem

\section{INTRODUCTION}

In Moradabad city most of the students are local and they come from a business background. If this student community is groomed in such a way that they get hands on experience of innovations, use of technology in setting up their own enterprise, they can generate their interest in entrepreneurship. The purpose is to encourage students to participate in new idea generation, use of Technology, setting up business, evaluating effective business ideas. Generally these types of students have a business background. They already have a family business in general this business is traditional one. In Moradabad city generally the focus of businessman is on exporting brass another metal handicraft items. However, it is observed that these traditional industries lacks the use of modern technology. If the students coming from the background with family business are developed with the entrepreneurial mindset and innovative thinking they may develop new technological equipment's that can be used to improve the output of their traditional industries. Entrepreneurship training give the student insight to critically analyze the resources available with them. They can also perform SWOT analysis of their business to incorporate newly acquired knowledge in their traditional business. The traditional business market in Moradabad City face various challenges such as competition, change in government policies, export rules, licensing, issues related to labor laws, pollution, health and safety issues of workers, use of conventional Technology etc. Students who have understood the concept of entrepreneurship and are also have technical background can help in developing solutions for their family business. Figure 1 shows a typical entrepreneurship ecosystem along with various stake holders. 


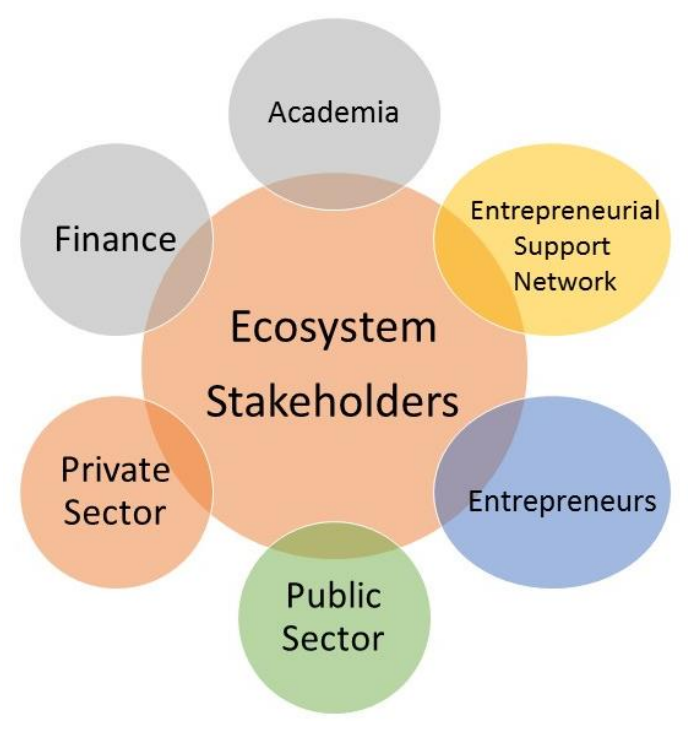

Figure 1: Entrepreneurship Ecosystem Stakeholder

\section{RELATED WORK}

Adner, R. \& Kapoor et.al in their paper titled "Value creation in innovation ecosystems: How the structure of technological interdependence affects firm performance in new technology generations" published in Strategic Management Journal suggested that the success of an company depends upon the efforts and innovations of its founders. They also addressed the challenges faced by external innovators which affect the focal firm's outcomes. They characterize the external environment according to the structure of interdependence [1]. Nambisan, S., \& Baron, in their paper titled "Entrepreneurship in Innovation Ecosystems: Entrepreneurs' Self-Regulatory Processes and Their Implications for New Venture Success" published in journal Entrepreneurship Theory and Practice presented that an Innovation ecosystems have emerged as an important context for entrepreneurship. Ecosystem entrepreneurs, however, face a unique set of challenges associated with the need to balance the goals and priorities set by the ecosystem leader with the goals and priorities of the new venture [2].

F. Kitsios, N. Papachristos and M. Kamariotou, et.al in their paper titled "Business Models for Open Data Ecosystem: Challenges and Motivations for Entrepreneurship and Innovation," published in IEEE 19th Conference on Business Informatics proposed that Open data provide many opportunities for businesses, such as the development of new products and services. A significant challenge for businesses and governments is the collaboration among actors who provide data, actors who consume data and actors who create new services and applications around the data. These actors synthesize a collaborative environment-called ecosystem [3].

K. Manivannan et.al in their paper titled "An Emerging Optimum Model For Achieving Excellence In Engineering Education Through Quality, Innovation And Entrepreneurship," published in World Engineering Education Forum presented the idea that The Engineering Education system has witnessed a plethora of changes in terms of deliverables responding to the continual changes in the social, economical and technological environments. The quality of the education system not only represents the industry ready graduates but also the sociably acceptable engineers with values [4]. P. C. Ensign and P. Leupold, et.al in their paper titled "Grassroots Opportunities for Innovation, Technology, and Entrepreneurship: Makerspaces in Non-Urban Communities," published in International Conference on Management of Engineering and Technology that revolution has been underway in creating, innovating, and making things. This exploratory study extends our knowledge of makerspaces located in small-medium sized/non-urban communities. We found the seeds of true "grassroots" innovation, technology and entrepreneurship are being initiated in the context of small to medium sized and rural communities [5].

R. Gupta, K. Miyazaki and Y. Kajikawa, et.al in their paper titled "Ingredients of Successful Emerging Business Ecosystems: Case of Industrial IoT Adoption," published in Portland International Conference on Management of Engineering and Technology (PICMET), presented an emerging business ecosystem 
presents a future new value creation opportunity for firms that choose to collaborate effectively in a timely manner. This paper combines innovation diffusion, systems transition, innovation systems and business ecosystem literature to identify ingredients in ecosystem dependent firms [6]. C. Bandera and E. Thomas, et.al in their paper titled "The Role of Innovation Ecosystems and Social Capital in Startup Survival," published in IEEE Transactions on Engineering Management presented Innovation ecosystems, including technology parks and incubators, endeavor to achieve a high density of startups that is rich in social capital to help tenants evolve [7]. Given the importance of social capital on startup success and the opportunity for social capital diffusion in high-density ecosystems, the inconclusive impact of ecosystems on firm performance warrants further attention. They presented a startup survival model that distinguishes between access to social capital and using it. From the literature study it is evident there exists a requirement to develop an entrepreneurial mindset among engineering system so that they can take up the challenges occurring in setting up own enterprise or creating innovations in their family business setup.

\section{Sample Case Study of a Metal Handicraft Brass Industry LOCATED IN MORADABAD CiTY}

A simple model as shown in figure 2 depicting model for problem identification, innovation and product development or proposed solution can be adopted for innovations in local brass /handicraft industry. In this paper a typical case of metal handicraft brass industry located in Moradabad city is considered. Students were having family business of polishing the metal handicraft. They observed there existed a problem of black dust while polishing the handicraft items. This dust was not only harmful for the workers as they inhaled it while working on the Machines, it also resulted in pollution. So using their technical knowledge they decided to provide solution for this problem. They designed a dust collector unit which can be used in the polishing machines in brass industries. They Deployed temple dust collectors in their own family set up for testing and field trials. Once their prototype was successful, they starting taking feedback about the product from the workers. The incorporated the suggestions of the workers for the improvement of the product. For example some of the workers suggested that the dust collector should have inbuilt light facility, it should be adjustable and should have wheels. Student made necessary changes to the design and improved their design [8-11].
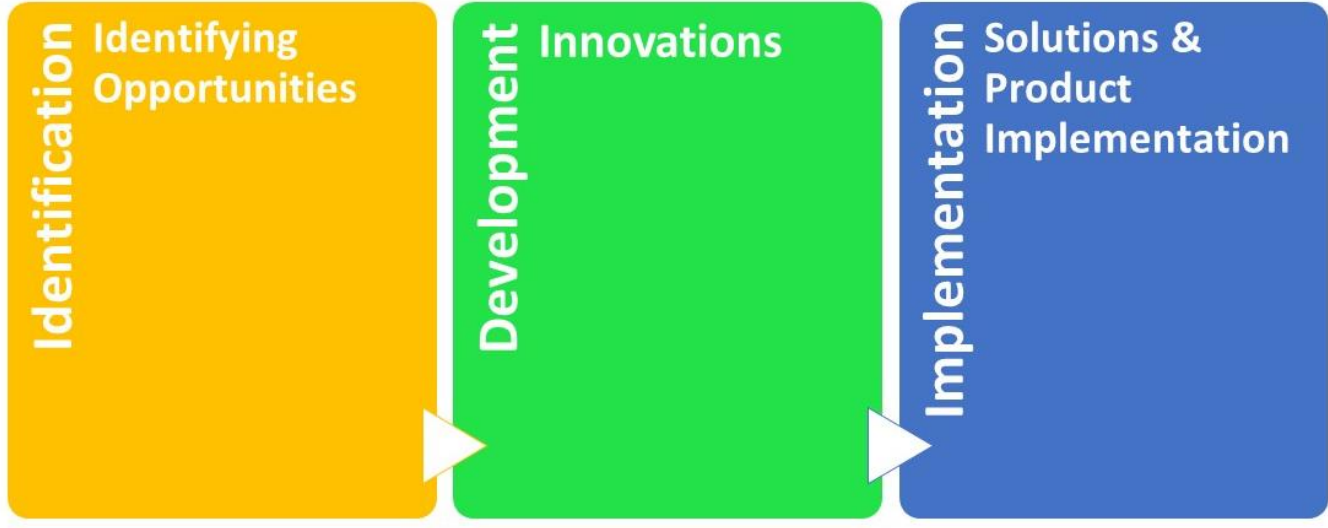

Figure 2: Model for problem identification, innovation and product development

\section{DisCuSSION}

The above discussed inputs emphasize clearly on the fact students with entrepreneurship mindset and technical background can develop various solutions to industrial problems which traditional business are facing. Help of the creativity and innovation they can provide solution to the industrial challenges. In the process students develop characteristics of successful entrepreneurs, they also become aware of market factors, challenges in business, their own entrepreneurial personality and its importance running of successful business enterprise. 


\section{CONCLUSION}

Including entrepreneurship in curriculum serves as a proprietary tool to make the students ready for starting new venture, startup, set up an enterprise. Once the acquire entrepreneurial skill set, this knowledge can be used for management of their own family business, give solutions to the problem faced by the local industry, as well as to become potential entrepreneurs. The role of colleges and educators is to provide knowledge about entrepreneurship, business management skills and knowhow of how to work an idea and convert it into a product or enterprise. The students coming from the business background can easily apply their technical knowledge to propose solutions and improve the business and productivity of their traditional family business.

\section{REFERENCES}

[1]. Adner, R. \& Kapoor, R. (2010). Value creation in innovation ecosystems: How the structure of technological interdependence affects firm performance in new technology generations. Strategic Management Journal, 31, 306-333.

[2]. Nambisan, S., \& Baron, R. A. (2013). Entrepreneurship in Innovation Ecosystems: Entrepreneurs' SelfRegulatory Processes and Their Implications for New Venture Success. Entrepreneurship Theory and Practice, 37(5), 1071-1097. https://doi.org/10.1111/j.1540-6520.2012.00519.x

[3]. F. Kitsios, N. Papachristos and M. Kamariotou, "Business Models for Open Data Ecosystem: Challenges and Motivations for Entrepreneurship and Innovation," 2017 IEEE 19th Conference on Business Informatics (CBI), Thessaloniki, 2017, pp. 398-407.

[4]. K. Manivannan, Y. Vijaya Kumar and M. K.V., "An Emerging Optimum Model For Achieving Excellence in Engineering Education through Quality, Innovation and Entrepreneurship," 2018 World Engineering Education Forum - Global Engineering Deans Council (WEEF-GEDC), Albuquerque, NM, USA, 2018, pp. 1-4.

[5]. P. C. Ensign and P. Leupold, "Grassroots Opportunities for Innovation, Technology, and Entrepreneurship: Makerspaces in Non-Urban Communities," 2018 Portland International Conference on Management of Engineering and Technology (PICMET), Honolulu, HI, 2018, pp. 1-7.

[6]. R. Gupta, K. Miyazaki and Y. Kajikawa, "Ingredients of Successful Emerging Business Ecosystems: Case of Industrial IoT Adoption," 2018 Portland International Conference on Management of Engineering and Technology (PICMET), Honolulu, HI, 2018, pp. 1-6.

[7]. C. Bandera and E. Thomas, "The Role of Innovation Ecosystems and Social Capital in Startup Survival," in IEEE Transactions on Engineering Management, vol. 66, no. 4, pp. 542-551, Nov. 2019.

[8]. K.Shinghal, A. Saxena, "Developing Entrepreneurial Mindset in Engineers", International Journal of Scientific Research and Management Studies (IJSRMS), Volume 4 Issue 2, pp. 56-59, Sept. 2017.

[9]. K.Shinghal, A. Saxena, "Effective Entrepreneurship Education through Teaching Case", International Journal of Engineering Sciences \& Emerging Technologies, Volume 10, Issue 3, pp: 82-84, Mar. 2018.

[10]. Kshitij Shinghal, Amit Saxena, "Importance of Nurturing Entrepreneurship Skills in Students", International Journal of Recent Trends in Electrical \& Electronics Engg. (IJRTE), Volume 7, Issue 1, pg 13-16, Aug., 2018.

[11]. A. Saxena, K. Shinghal, R. Misra and A. Agarwal, "Automated Enhanced Learning System using IOT," 2019 4th International Conference on Internet of Things: Smart Innovation and Usages (IoT-SIU), Ghaziabad, India, 2019, pp. 1-5.

\section{AUTHORS BIOGRAPHY}

Kshitij Shinghal has 19 Years of experience in the field of Academic and is actively involved in research \& development activities. He obtained his Doctorate degree from Shobhit University Meerut in 2013, Masters degree (Digital Communication) in 2006 from UPTU, Lucknow. He started his career from MIT, Moradabad. Presently he is working as an Associate Professor, Deptt of E\&C Engg., at MIT Moradabad. He has published number of papers in national journals, conferences and seminars. He has guided two Masters, more than sixty

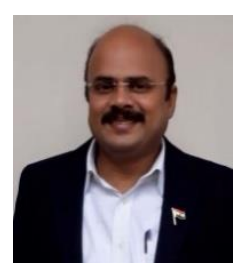


International Journal of Advances in Engineering \& Technology, Dec., 2019. CIJAET

ISSN: 22311963

students of B. Tech, and guiding three Ph.D. \& M. Tech. theses. He is an active Member of Various Professional Societies such as ISTE, IACSIT, IAENG etc.

Amit Saxena has 14 Years of experience in the field of Academic. He started his career from MIT, Moradabad. Presently he is working as an Assistant Professor, Deptt of E\&C Engg., at MIT Moradabad. He obtained his Bachelor's degree in Electronics \& Communication Engineering from I.E.T., Rohilkhand University, Bareilly and Masters degree (VLSI Design) in 2009 from UPTU, Lucknow. He has published number of papers in international \& national journals, conferences and seminars.

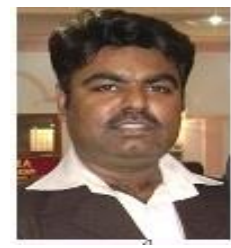

